\title{
The investigation of the microstructure behavior of the spray distances and argon gas flow rates effects on the aluminum coating using self-generated atmospheric plasma spray system
}

\author{
Sh. Khandanjou ${ }^{1} \cdot$ M. Ghoranneviss ${ }^{1} \cdot$ Sh. Saviz $^{1}$
}

Received: 31 January 2017/ Accepted: 19 June 2017/Published online: 29 June 2017

(c) The Author(s) 2017. This article is an open access publication

\begin{abstract}
In the present paper, our aims are the investigation of the effects of the spray parameters of the aluminum-coated layer on the microstructure and mechanical properties. For this purpose, we use the self-generated atmospheric plasma spray system for coating of aluminum on the carbon steel substrate to protect it against corrosion degradation. This system allows us to achieve the best choice for parameters. In this paper, the effects of spray distance and argon flow rate on the characteristics of aluminum coating are investigated. To obtain the results, the analyses are used such as X-ray diffraction, scanning electron microscope, micro hardness of the coating by Vickers method, and adhesion strength behaviors by pulloff test. The results show that the porosity increases with increasing distance. This phenomenon reduces the hardness and adhesion, which is clearly evident in our results. The other important conclusion is that, if the gas flow rate increases, the porosity decreases. It is shown that the best adhesion strength is obtained at the special value of the spraying distance.
\end{abstract}

Keywords Thermal plasma spray · Porosity ·

Micro hardness · Adhesion strength

M. Ghoranneviss

Shahrooz.saviz@srbiau.ac.ir

1 Plasma Physics Research Centre, Science and Research Branch, Islamic Azad University, Tehran, Iran

\section{Introduction}

Thermal plasma spray is one of the advanced methods in coating technology for surface protection in various industrial fields [1-3]. In thermal plasma spray processes, the powder is fed into the plasma flame most commonly via powder feeder system that is mounted near the anode nozzle exit. The rapidly melted powder is accelerated toward the substrate surface and deposited to form a coating [4]. The performance of a plasma spray coating depends on various parameters such as, plasma power, gas flow rate, stand-off distance and design of plasma spray gun [5-8].

Many studies have been done on the effects of spray on the coating properties and hardness. Wang and et al. [9] reported that plasma spray parameters could affect the speed of the particles. They found that the particle velocity increases with the argon and hydrogen flow rate, but the electric current has a minor effect on the velocity relatively. They also show that these effects can affect the porosity and hardness of the coating. Zhang et al. [10] studied the relation between gas flow rate and porosity of the supersonic plasma sprayed Ni-based coating. They show that the porosity of the coating increase by decreasing the hydrogen flow rate. Also they show that, when the powder feed rate is relatively low, the existence of the micro-cracks in the coating influenced micro hardness. Several studies [11-13] reported the effects of plasma spray parameters on porosity and micro hardness of coatings, too.

Unfortunately, few reports $[14,15]$ are currently available on the effect of plasma spray parameters on aluminium coatings. In these researches, Vautherin et al. coated aluminium powder by very low pressure plasma spraying (VLPPS) process and studied the effect of powder 
size distribution and spray distance on phase composition, microstructure and micro hardness of aluminium plasma spray coatings. They found that the micro hardness of the coating is increased when powder size distribution is reduced and spray distance is increased from 650 to $800 \mathrm{~mm}$. Moreover, it has been found that the performance of low pressure plasma spray aluminium coating is strongly dependent on flattening behavior of the deposited particles, which are closely related to spraying parameters.

In this study, an attempt has been made to understand the influence of gas flow rate and stand-off distance of handmade atmospheric plasma torch on porosity and mechanical properties of aluminium coating. The aluminium is chosen as a demonstrative material due to its application in various industries as corrosion protective material $[16,17]$ and its moderate vaporization enthalpy (i.e., $38.23 \mathrm{KJ} \mathrm{cm}^{-3}$ ) [14] is compared to the other metals. In the present research a series of aluminium coatings are prepared at various gas flow rate and distance under fixed input power. The influence of these parameters on microstructure, porosity, micro hardness and adhesion strength of atmospheric plasma sprayed aluminium coatings are studied in detail. Due to the high energy plasma torch and a low melting point of aluminium, it is important to fine-tune the system parameters. The flexibility in research is very high due to the fact that the system is handmade.

\section{Experimental details}

A plasma spray system is developed in Plasma Physics Research Centre. It is used to deposit the coating in the present study. Figure 1a, b shows the schematic diagram of plasma torch and plasma torch in operation, respectively. Argon is used as plasma torch main gas and powder feed gas. Some technical specifications of the plasma spray system are given in Table 1.

Figure 2 shows the X-ray diffraction pattern and morphology of aluminum powder. Aluminum-molten particles are deposited vertically $\left(\theta=90^{\circ}\right)$ on the surface of the substrate using plasma torch at different stand-off distance and different work gas flow rate. In this study, a low carbon steel sheet with $3 \mathrm{~mm}$ thickness is selected as substrate.
Fig. 1 a The schematic diagram of plasma torch b plasma system in operation

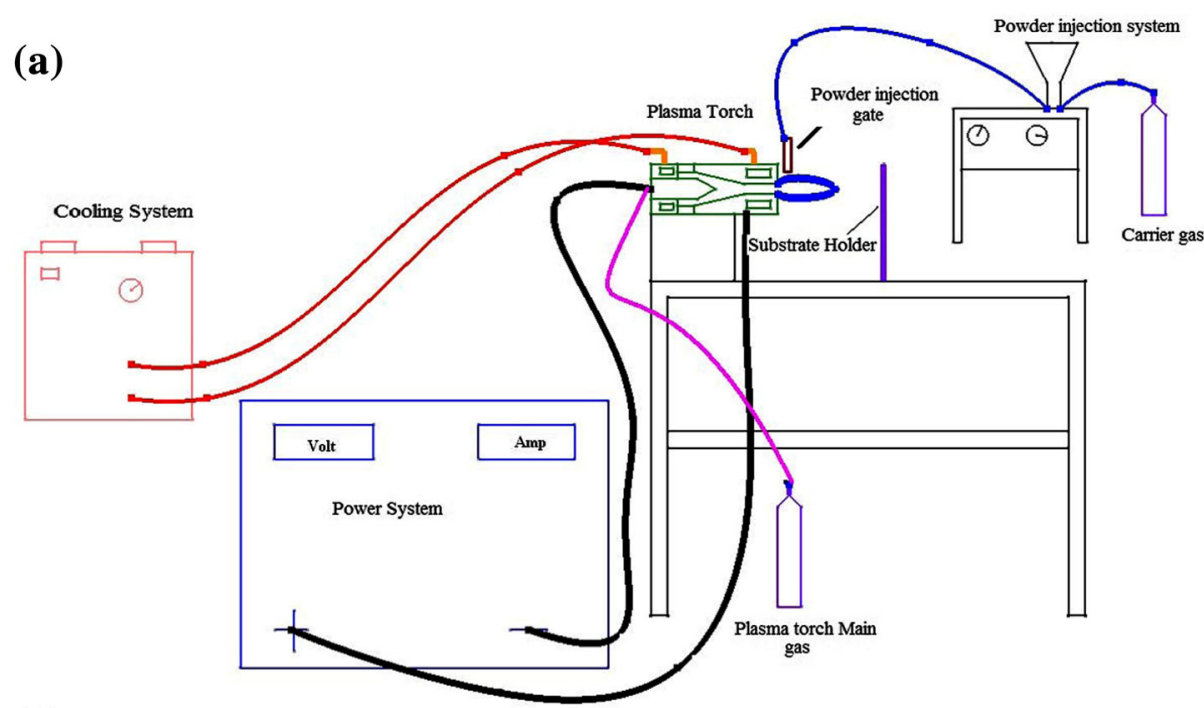

(b)

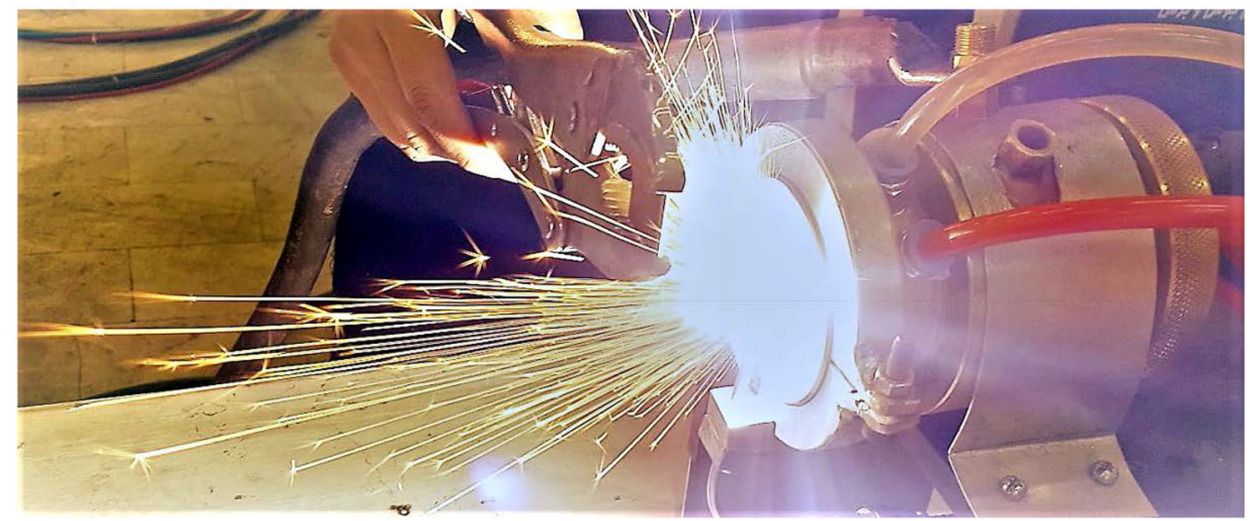


Table 1 Process parameters used for Al coating

\begin{tabular}{ll}
\hline Variable parameters & Unit \\
\hline Working gas & Argon \\
Voltage (V) & 50 \\
Current (A) & 600 \\
Nozzle diameter $(\mathrm{mm})$ & 5 \\
Powder feeding rate $\left(\mathrm{g} \mathrm{min}^{-1}\right)$ & 20 \\
Spray angle & $90^{\circ}$ \\
Substrate temperature & Room temperature
\end{tabular}
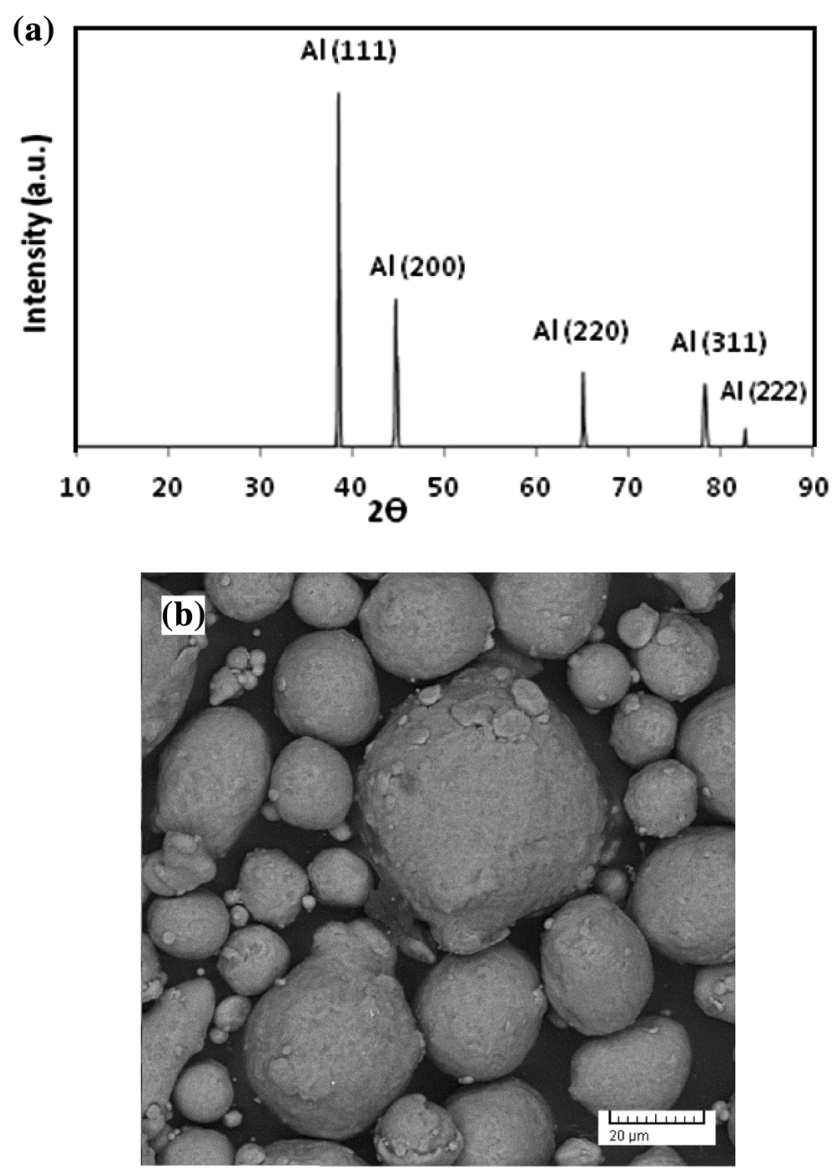

Fig. 2 a XRD pattern and $\mathbf{b}$ morphology of $\mathrm{Al}$ powder

The surfaces of the substrates are grit-blasted with $\mathrm{Al}_{2} \mathrm{O}_{3}$ grits prior to coating to enhance the adhesion of the coating. Spherical-shaped aluminum powders are used as feedstock material in the size range between 20 and $75 \mu \mathrm{m}$. It is commercially available pure aluminum with purity about $99.5 \mathrm{wt} \%$. The aluminum powder is deposited vertically $\left(\theta=90^{\circ}\right)$ on the surface of the substrate using plasma torch. The powder is injected inside the plasma flame vertically with the aid of the METCO company standard powder feeding system. In this paper, the distance of spray and flux of gas is changed to achieve the best results in terms of microstructure and corrosion-resistant.

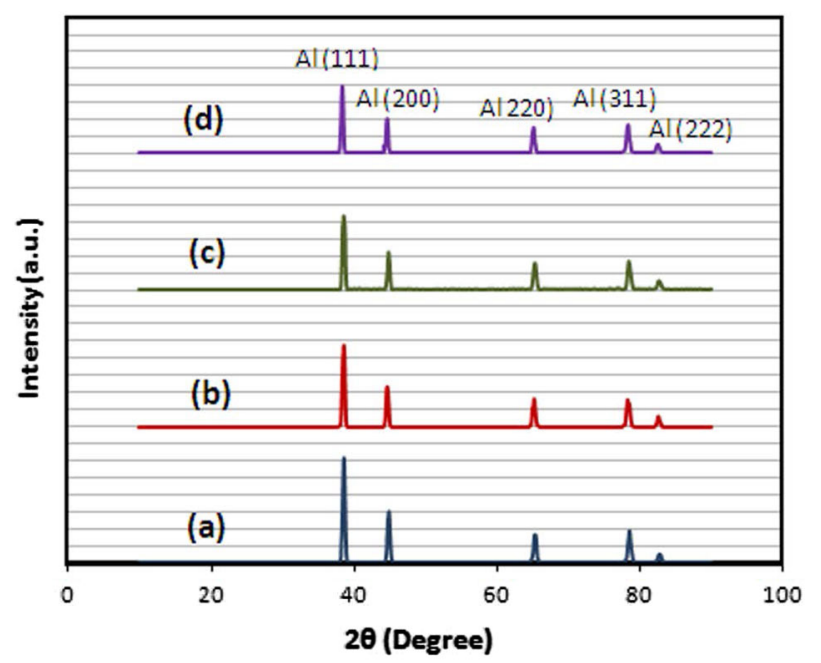

Fig. 3 XRD pattern of $\mathrm{Al}$ coating at a 80, b 100, c 120 and d $140 \mathrm{~mm}$ stand-off distance $(P=15 \mathrm{~kW}$ and argon flow rate $=40 \mathrm{~L} \mathrm{~min}^{-1}$ )

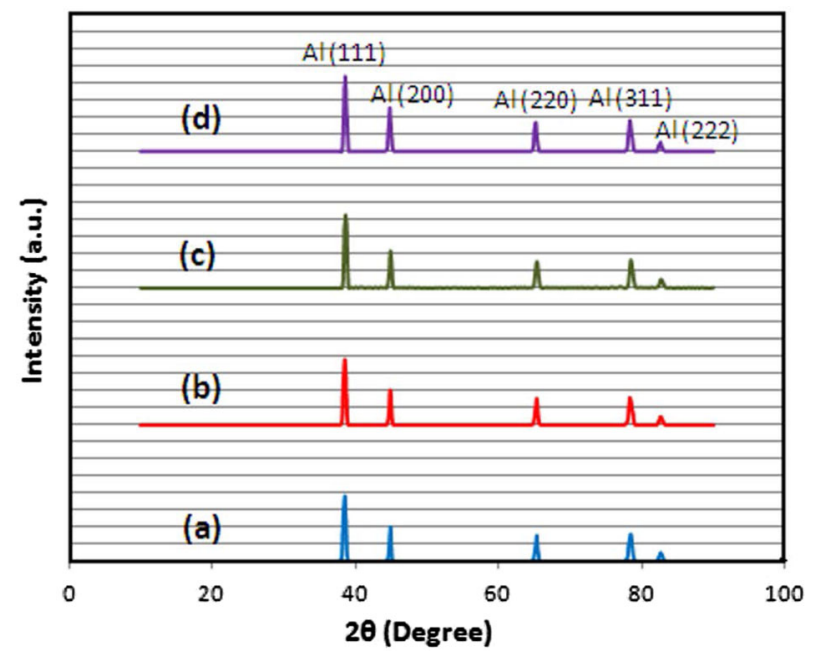

Fig. 4 XRD pattern of $\mathrm{Al}$ coating at a 30, b 35, c 40 and d $45 \mathrm{~L} \mathrm{~min}^{-1}$ gas flow rate $(P=15 \mathrm{~kW}$ and stand-off distance $=120 \mathrm{~mm}$ )

After the deposition of aluminium powder on low carbon steel substrate, the coated layers are analyzed with $\mathrm{X}$-ray diffraction (XRD, STADI-MP) with $\mathrm{Cu} \mathrm{K} \alpha$ radiation $\left(\lambda=1.54056 \mathrm{~A}^{\circ}\right)$ and scanning electron microscope (SEM, VEGAII TESCAN) analysers.

The micro hardness of coatings is measured by Vickers micro hardness device (BUEHLER) at the polished cross section surface according to ISO/IEC17025 standard. The load applied to measure the micro hardness is $25 \mathrm{~g}$ for all samples. For each sample, the hardness value, taken at three different points of the cross section of aluminium coatings and the average values are recorded. The adhesion strength of the coating is determined with the pull-off device (DEFELESCO). 


\section{Results and discussions}

\section{XRD analysis}

\section{XRD evaluation for different stand-off distances}

The XRD patterns of aluminium coatings with 80, 100, 120, $140 \mathrm{~mm}$ standoff distance are shown in Fig. 3. The gas flow rate is kept constant at $40 \mathrm{~L} \mathrm{~min}^{-1}$. It is clear that the only distinguishable phase is pure aluminium (ICSD No. 00-004-0787) in all of the coatings. No other phases are detected due to their low concentration in the coatings. According to the reference data, the diffraction peaks at the $38.47^{\circ}, 44.74^{\circ}, 65.13^{\circ}, 78.23^{\circ}$ and $82.44^{\circ}$ can be associated with the X-ray diffraction from the (111), (200), (220),
(311) and (222) Bragg planes, respectively, for aluminium coating. Comparison of Fig. 3a-d shows that by increasing the stand-off distance, the intensity of peaks is changed. For example, when the stand-off distances are changed from 80 to $140 \mathrm{~mm}$, the intensity of phases including $\mathrm{Al}$ (111) decreases from 309 to 199 a.u. but for $\mathrm{Al}$ (311) intensity changes are not noticeable. It is shown that by decreasing the stand-off distance, the crystalline particles increase in the direction of $\mathrm{Al}$ (111), $\mathrm{Al}$ (200) and $\mathrm{Al}$ (220) peaks.

\section{XRD evaluation for different gas flow rates}

Figure 4 shows the XRD pattern of aluminium coating with $30,35,40$ and $45 \mathrm{~L} \mathrm{~min}^{-1}$ argon flow rates. It is clear that
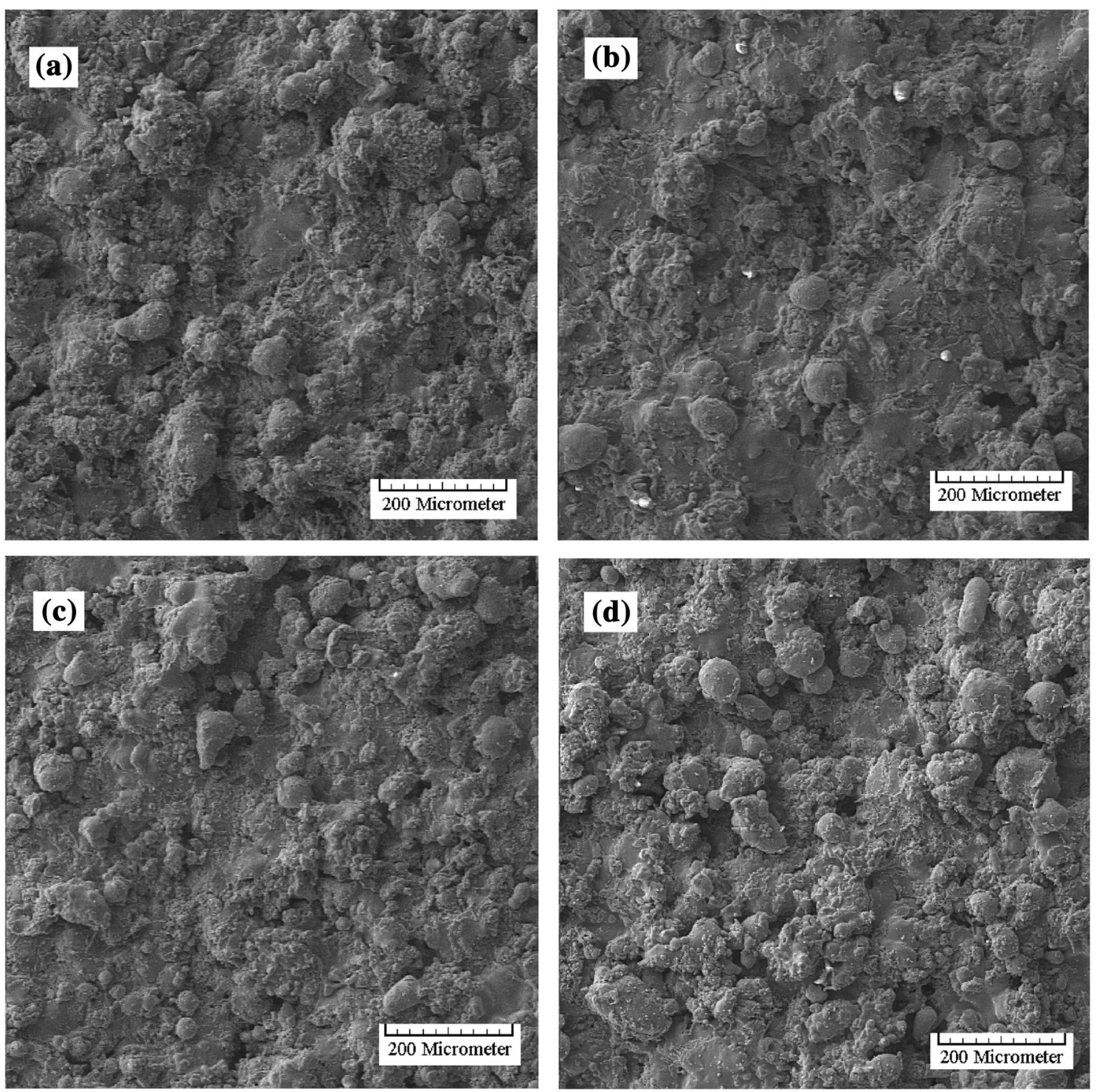

Fig. 5 The morphology of aluminum coating at different stand-off distance a 80, b 100, c 120 and d $140 \mathrm{~mm}(P=15 \mathrm{~kW}$ and argon flow rate $=40 \mathrm{~L} \mathrm{~min}^{-1}$ ) 
no other phase is detected, just like XRD pattern of aluminium coating at different stand-off distance. Comparison of Fig. $4 a-d$ is shown that the highest intensity of peaks appears at highest gas flow rate. This means that by increasing gas flow rate, the intensity of peaks increase slightly. The greatest change is occurred in the intensity of $\mathrm{Al}$ (111) peak. When the argon flow rate is changed from 30 to $45 \mathrm{~L} \mathrm{~min}^{-1}$, the intensity of $\mathrm{Al}$ (111) peak increases from 190 to 220 a.u. In other phases, the changes are inconsiderable. It means that by increasing gas flow rate, the crystalline particles in direction of Al (111) peak are increased.
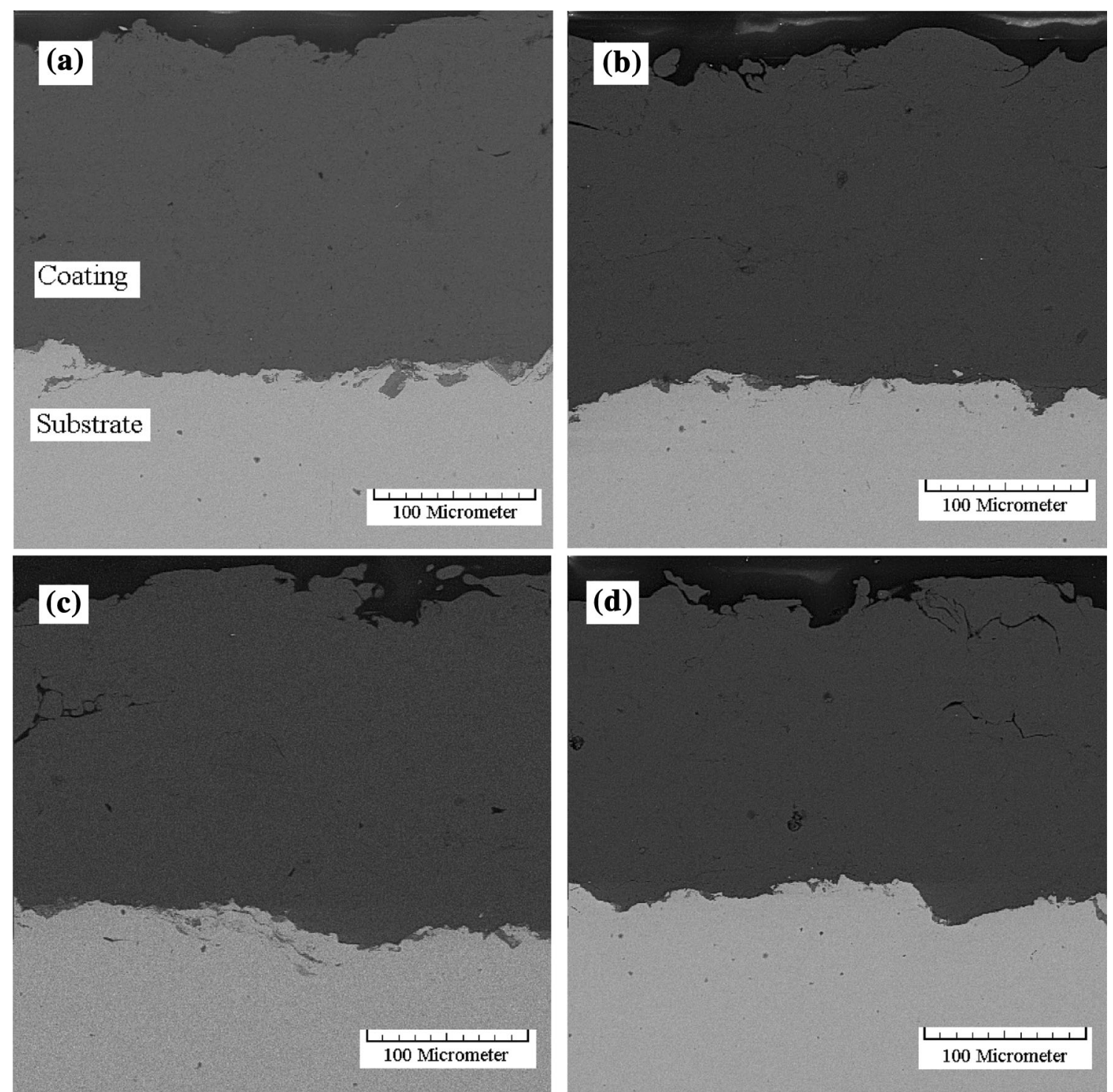

Fig. 6 The morphology of cross section of aluminum coating at different stand-off distance a 80, b 100 , c 120 and $\mathbf{d} 140 \mathrm{~mm}(P=15 \mathrm{~kW}$ and argon flow rate $=40 \mathrm{~L} \mathrm{~min}^{-1}$ ) 
Figure 6 shows the cross section of aluminum coating at different spray distances. It is clear that the porosities of the coatings are increased by increasing the stand-off distance. The porosity percentage analysis was done by gray-scale threshold with image analysis software (IMAGEJ), using the SEM images of the cross section. Porosity was defined as area of void spaces in percentage of the total area of the coating [18]. With the aid of the Image J software, the percents of the porosities are calculated in which for 80 , 100,120 and $140 \mathrm{~mm}$ stand-off distances are 1.50, 1.90, 2.62 and $2.66 \mathrm{vol} \%$, respectively. The physical reason is that when the spray distance is increased to the value $140 \mathrm{~mm}$, not only the particles cooled but also their velocities are reduced. This will lead to the greater number of un-melted particles resulting in higher porosity [19]. For conventional plasma jet used for thermal spraying, plasma temperature decreases along the torch axis from the exit. So, the surface temperature usually decreases when the particles travel over $80-100 \mathrm{~mm}$ from the nozzle. This usually causes a decreasing tendency of coating porosity with increasing spray distance.

\section{Microstructural analysis for different gas flow rates}

Figure 7 shows the morphology of aluminum coatings at different gas flow rates. The figure is shown that the coating is produced by well-molten particles. The evaluation of the cross section of the coating is shown in Fig. 8. The porosity percentage is calculated by Image $\mathbf{J}$ software. As seen in this figure the porosity of the coating decreases by increasing the
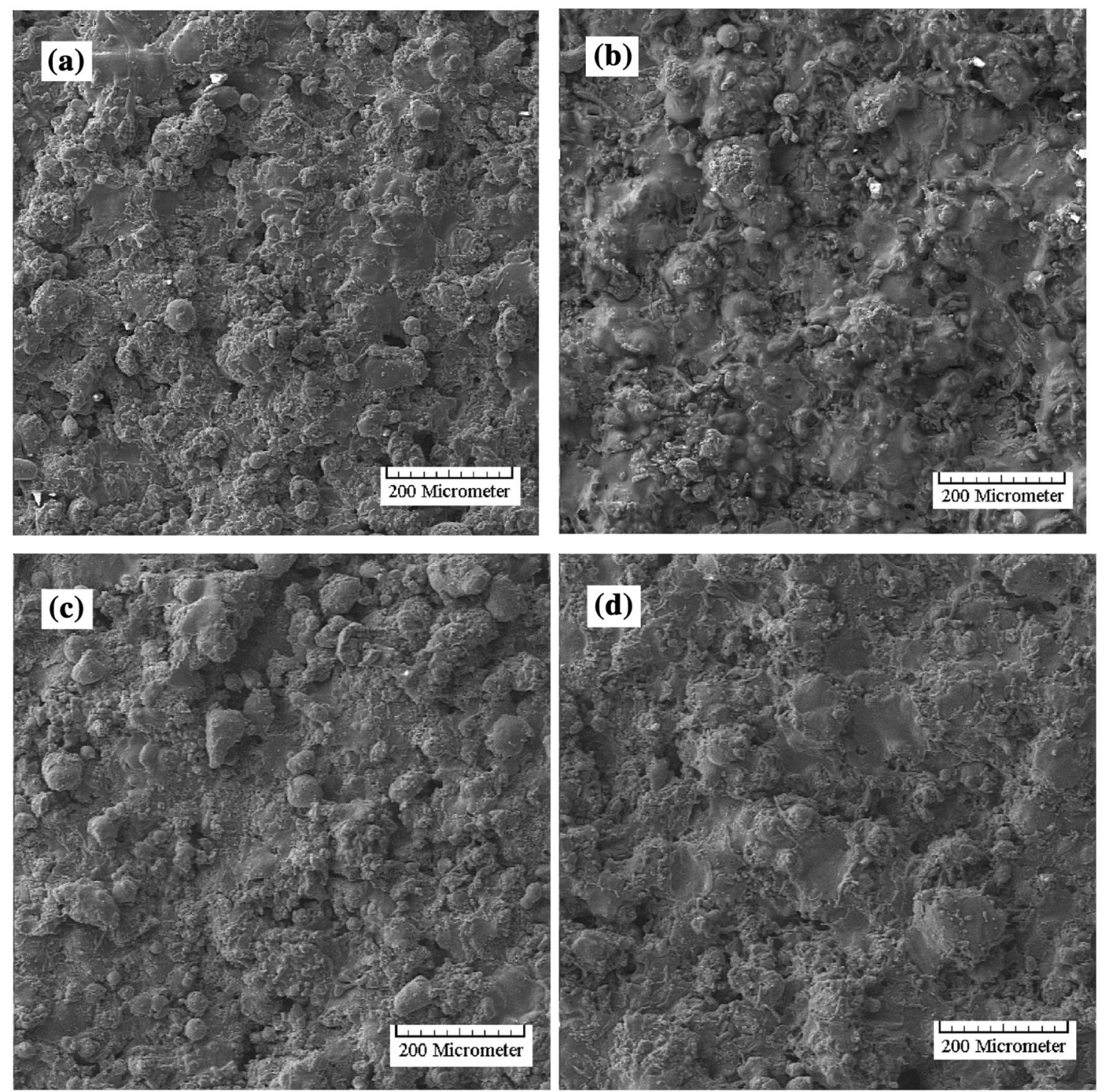

Fig. 7 The morphology of aluminum coatings with different argon flow rate: a 30, b 35, c 40 and d $45 \mathrm{~L} \mathrm{~min}^{-1}(P=15 \mathrm{~kW}$ and stand-off distance $=120 \mathrm{~mm}$ ) 

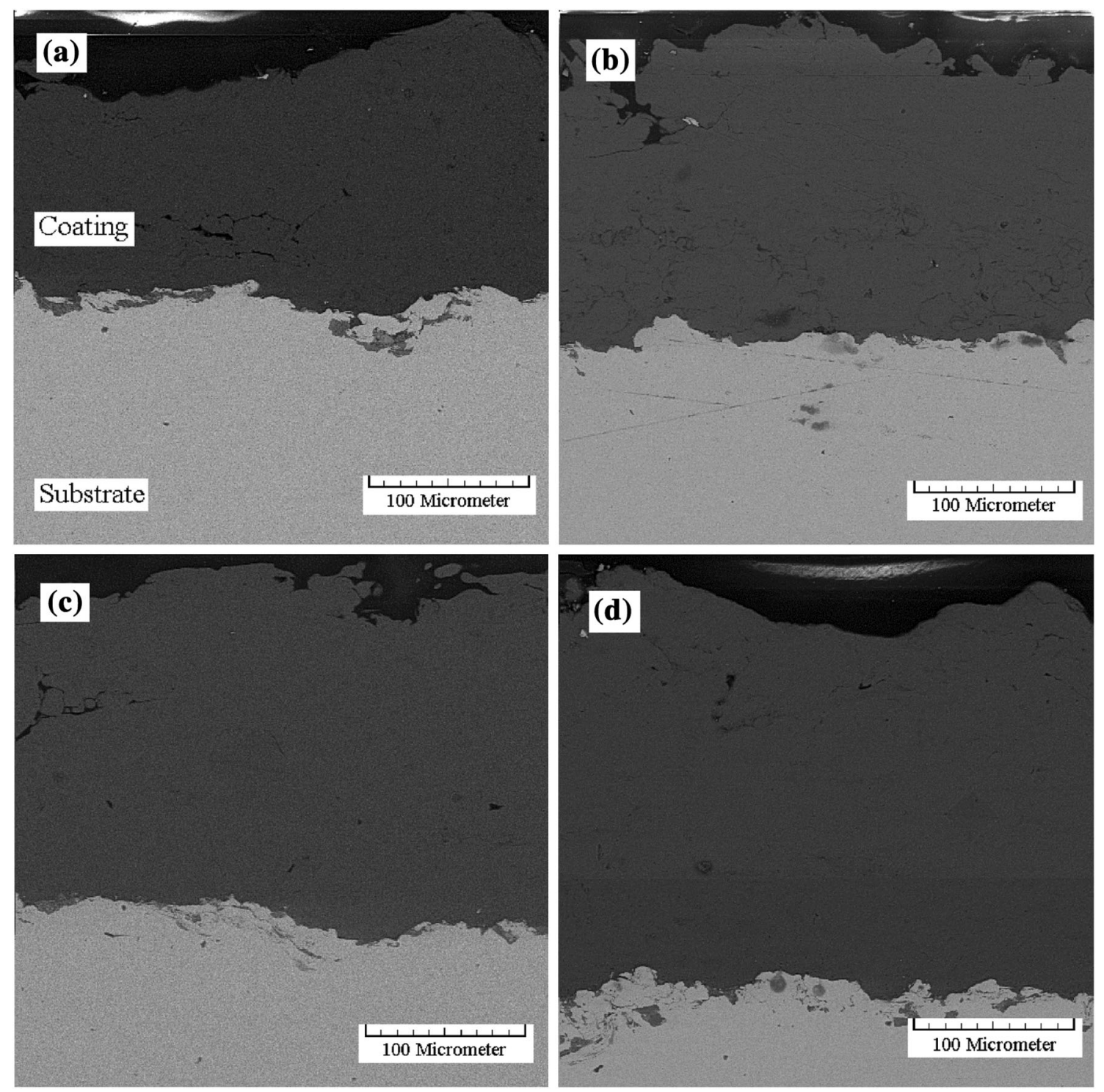

Fig. 8 The morphology of cross section of aluminum coatings with different argon flow rate: a 30, b 35 , c 40 and d $45 \mathrm{~L} \mathrm{~min}{ }^{-1}(P=15 \mathrm{~kW}$ and stand-off distance $=120 \mathrm{~mm}$ )

argon gas flow rate. The porosity percent values for 30,35 , 40 and $45 \mathrm{~L} \mathrm{~min}^{-1}$ gas flow rate are 3.08, 2.91, 2.62 and $1.96 \mathrm{vol} \%$, respectively. The physical reason of this phenomenon is that the particle velocity is increased with increasing gas flow rate. Such effect is attributed to the increase in plasma velocity resulting from an improved thermal pinching effect on plasma jet with an increase in gas flow rate. As for molten spray droplet, an increase in particle velocity leads to increase in impacting pressure of the molten droplet to the substrate surface, which results in a more intimate contact between the flowing liquid and substrate surface. So, with increasing argon flow rate, porosity of coating is decreased. As a result, the coating deposited at spray distance $120 \mathrm{~mm}$ with gas flow $40 \mathrm{~L} \mathrm{~min}^{-1}$ presented a dense microstructure consisting of well-flatted particles.

\section{Micro hardness analysis}

Micro hardness analysis for different spray stand-off distances

Figure 9 shows the graph of micro hardness and porosity versus stand-off distance. For aluminum coatings at 80 , 100,120 and $140 \mathrm{~mm}$ distance, the average value of micro hardness are calculated that are $38 \mathrm{Hv}_{0.025}, 37 \mathrm{Hv}_{0.025}, 35$ $\mathrm{Hv}_{0.025}$ and $35 \mathrm{Hv}_{0.025}$, respectively. This means that, by increasing stand-off distance, the average value of micro hardness is decreased. Figure 9 also shows that the micro hardness of coating is increased with decreasing porosity. The physical meaning of this phenomenon is that, as previously mentioned, the temperature of the plasma jet is 


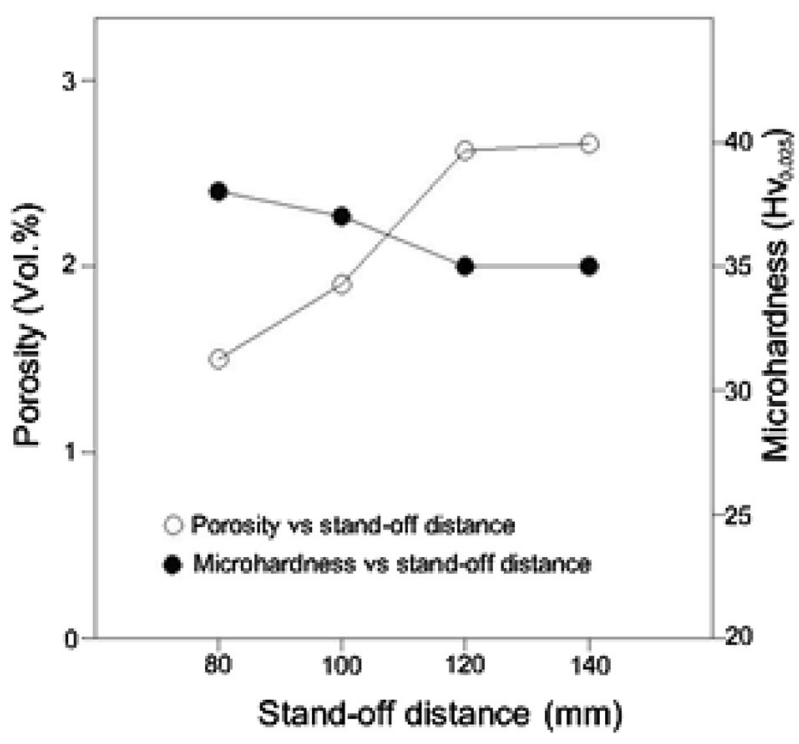

Fig. 9 The graph of micro hardness and porosity versus stand-off distance $\left(P=15 \mathrm{~kW}\right.$ and $\operatorname{argon}$ flow rate $\left.=40 \mathrm{~L} \mathrm{~min}^{-1}\right)$

decreased along the torch axis from the nozzle. Therefore, the particles surface temperature is usually decreased by increasing the distance from the nozzle exit. It is shown that the coating micro hardness decreases by increasing the spray distance. Thus, by increasing the stand-off distance, the porosity of the coating is increased and micro hardness value is decreased. When the spray distance was increased, only relatively large particles still in molten state but at low temperature were preferably deposited in the coating. This led to formation of the coatings with deformed particles. As a result, the deposited coating presented a low hardness.

\section{Micro hardness analysis for different gas flow rates}

The graph of porosity and micro hardness versus work gas flow rate of aluminum coatings is shown in Fig. 10. The average value of micro hardness for aluminum coating at $30,35,40$ and $45 \mathrm{~L} \mathrm{~min}^{-1}$ is $33 \mathrm{Hv}_{0.025}, 35$ $\mathrm{Hv}_{0.025}, 35 \mathrm{Hv}_{0.025}$ and $36 \mathrm{Hv}_{0.025}$, respectively. Thus, it is concluded that the micro hardness increases by increasing the gas flow rate. Figure 10 also shows the relation between porosity and micro hardness value. The porosity in contrast to micro hardness decreases by increasing the gas flow rate. The physical reason for this phenomenon is that the particle velocity increases by increasing the argon gas flow rate. An increase in particle velocity also leads to an increase in impacting pressure of the molten particle to substrate surface. So the flattening ratios of the molten particles are increased with increasing particle velocity during aluminum plasma spraying process. A higher particle velocity caused a more sufficient spreading and an improved

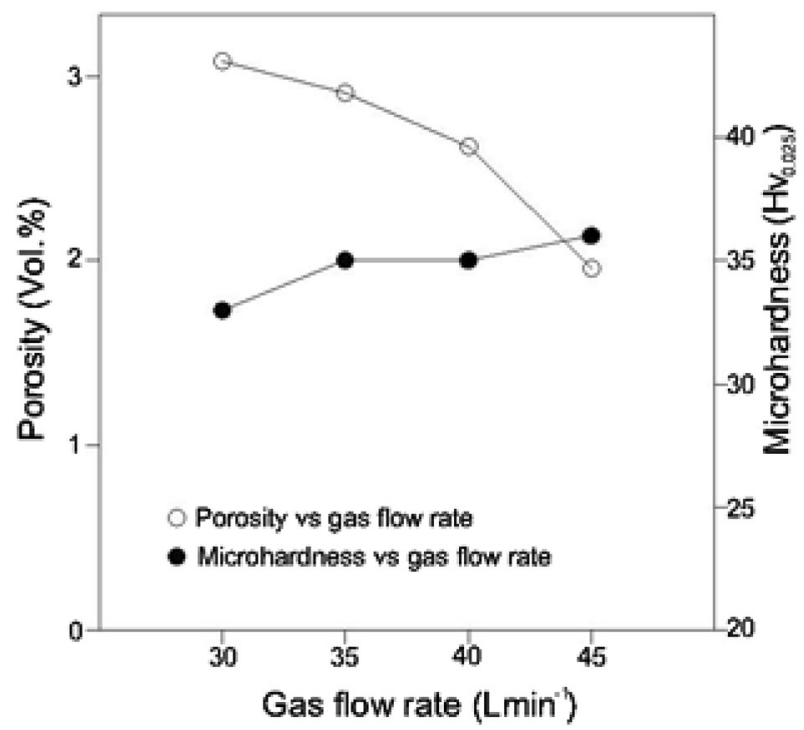

Fig. 10 The graph of porosity and micro hardness versus work gas flow rate $(P=15 \mathrm{~kW}$ and stand-off distance $=120 \mathrm{~mm})$

contact between deposited layers, which tends to increase the cooling rate of splats. On the other hand, increasing the plasma velocity improves the thermal pinching effect of the plasma jet. The thermal pinching effect resulting from the increase of gas flow will improve the heating of plasma jet to spray particles as well. So, the dense microstructure consisting of wellflattened particles can be formed in the coating. Therefore, the porosity of the coating is decreased by increasing the argon flow rate and the micro hardness of the coating is increased.

\section{Pull-off test}

\section{Pull-off test for different stand-off distances}

Figure 11 shows the graph of adhesion strength and porosity versus stand-off distance. It is interesting that the adhesion strength for distances 80,100 and $140 \mathrm{~mm}$ is 10.61, 11.14 and 9.51 MPa. So the best value for adhesion is obtained at a particular distance. The optimum stand-off distance is important to ensure good adherence of the coating bond. Too short distances produce lower adherence due to overheating, resulting in internal stress inside the coating. In contrast, too long distances decrease the adherence bonding due to cooling and deceleration of the particles flying in the plasma beam. In Fig. 11, we also investigate the relation between the porosity and adhesion. We show the porosity as a function of the stand-off distances in this graph.

The experimental results for different stand-off distance of aluminum coating are shown in Table 2. 


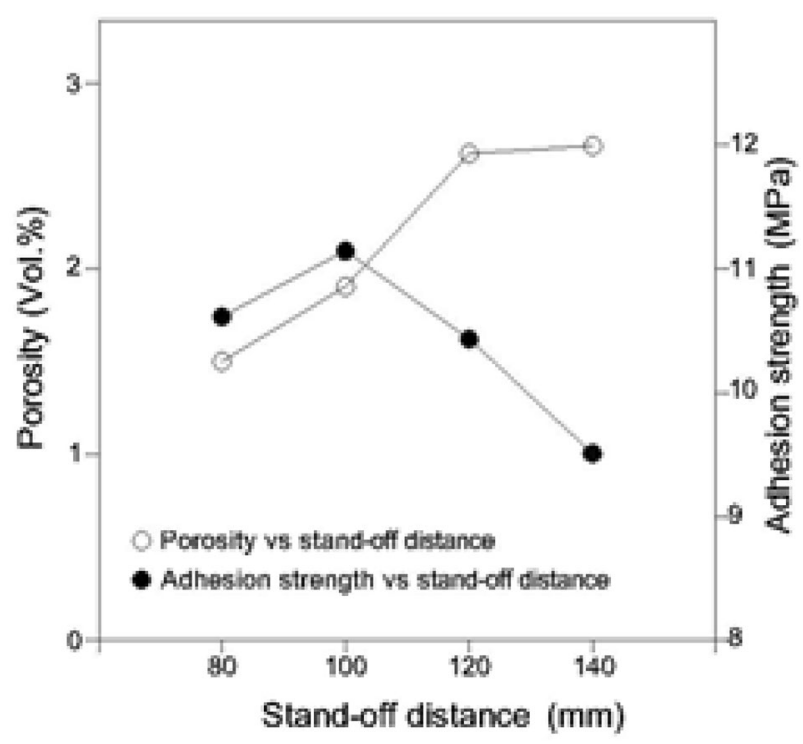

Fig. 11 The graph of adhesion strength and porosity versus stand-off distance $\left(P=15 \mathrm{~kW}\right.$ and argon flow rate $\left.=40 \mathrm{~L} \mathrm{~min}^{-1}\right)$

Table 2 The experimental results for different stand-off distance $\left(\right.$ argon flow rate $=40 \mathrm{~L} \mathrm{~min}^{-1}$ )

\begin{tabular}{llll}
\hline $\begin{array}{l}\text { Stand-off } \\
\text { distance }(\mathrm{mm})\end{array}$ & $\begin{array}{l}\text { Porosity } \\
(\mathrm{vol} \%)\end{array}$ & $\begin{array}{l}\text { Micro hardness } \\
\left(\mathrm{Hv}_{0.025}\right)\end{array}$ & $\begin{array}{l}\text { Adhesion } \\
\text { strength }(\mathrm{MPa})\end{array}$ \\
\hline 80 & 1.50 & 38 & 10.61 \\
100 & 1.90 & 37 & 11.14 \\
120 & 2.62 & 35 & 10.43 \\
140 & 2.66 & 35 & 9.51 \\
\hline
\end{tabular}

Pull-off test for different values gas flow rates

Figure 12 shows the graph of adhesion strength and porosity of aluminum coating versus argon flow rate. When the gas flow rate is increased from 30 to $45 \mathrm{~L} \mathrm{~min}^{-1}$, the adhesion strength of aluminum coating increased from 8.42 to $11.24 \mathrm{MPa}$. It means that the lowest adhesion strength is obtained at the lowest work gas flow rate and the highest adhesion strength is obtained at highest gas flow rate.

At higher gas flow rate, particles after deposition form a stronger bonding with the substrate surface on solidification due to their high velocity. A higher particle velocity has improved the contact between deposited layers. So, porosity of coatings is decreased and adhesion strength is increased by increasing gas flow rate. The results for different argon gas flow rate are given at Table 3.

\section{Conclusion}

In this study, aluminum powder is coated on low carbon steel substrate at different stand-off distances and different gas flow rates to investigate the effect of these parameters

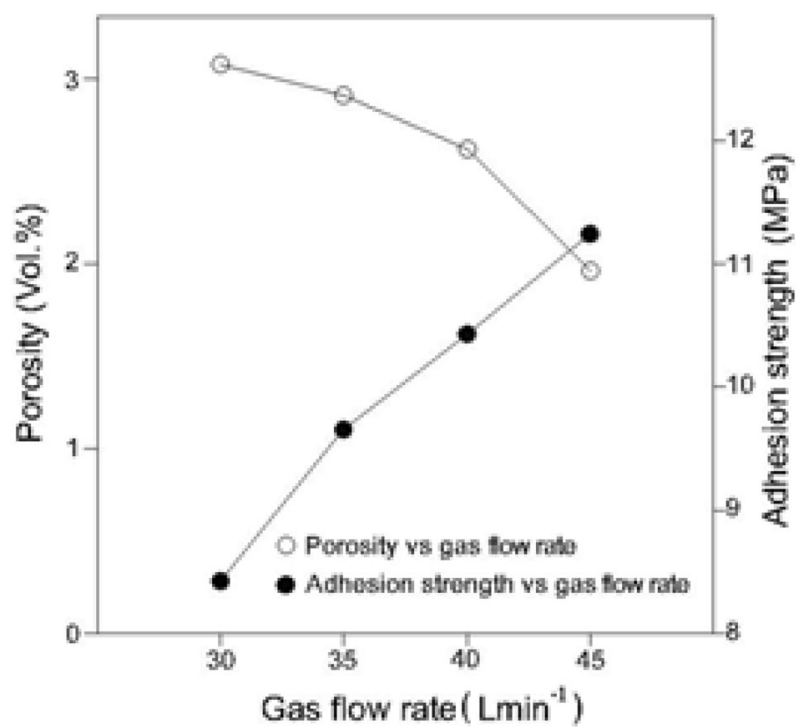

Fig. 12 The graph of adhesion strength and porosity versus work gas flow rate $(P=15 \mathrm{~kW}$ and stand-off distance $=120 \mathrm{~mm})$

Table 3 The experimental results for different argon gas flow rate (stand-off distance $=120 \mathrm{~mm}$ )

\begin{tabular}{llll}
\hline $\left.\begin{array}{l}\text { Argon flow rate } \\
(\mathrm{L} \mathrm{min}\end{array}{ }^{-1}\right)$ & $\begin{array}{l}\text { Porosity } \\
(\text { vol\%) }\end{array}$ & $\begin{array}{l}\text { Micro hardness } \\
\left(\mathrm{Hv}_{0.025}\right)\end{array}$ & $\begin{array}{l}\text { Adhesion } \\
\text { strength }(\mathrm{MPa})\end{array}$ \\
\hline 30 & 3.08 & 33 & 8.42 \\
35 & 2.91 & 35 & 9.65 \\
40 & 2.62 & 35 & 10.43 \\
45 & 1.96 & 36 & 11.24 \\
\hline
\end{tabular}

on morphology and mechanical properties of aluminum coatings. The important results are as follows:

1. The XRD pattern of coatings with different stand-off distances shows that the only distinguishable phase is pure aluminum. By increasing the stand-off distance, the intensity of peaks including $\mathrm{Al}$ (111) decreases but for $\mathrm{Al}$ (311) intensity changes are not noticeable.

2. The XRD pattern of coatings with different gas flow rates shows that the only highest intensity of peaks appears at highest gas flow rate. The intensity of $\mathrm{Al}$ (111) peak increases by increasing the gas flow rates and in other phases the changes are inconsiderable.

3. The un-melted particles can be clearly recognized at longer spray distances and the porosities of the coatings are increased by increasing the stand-off distance.

4. The porosity of the coating is decreased by increasing argon gas flow rate.

5. By increasing the stand-off distance, the average value of micro hardness is decreased and the porosity of the coating is increased. 
6. The micro hardness increases by increasing the gas flow rate and the porosity of the coating is decreased by increasing the argon flow rate.

7. The best value for adhesion is obtained at a particular distance.

Open Access This article is distributed under the terms of the Creative Commons Attribution 4.0 International License (http://crea tivecommons.org/licenses/by/4.0/), which permits unrestricted use, distribution, and reproduction in any medium, provided you give appropriate credit to the original author(s) and the source, provide a link to the Creative Commons license, and indicate if changes were made.

\section{References}

1. Fauchais, P.: Understanding plasma spraying. J. Phys. D Appl. Phys. 37(9), R86 (2004)

2. Rao, L., Rivard. F., Carabin, P.: Theramal plasma torches for metallurgical applications. In: 4th International Symposium on High Temperature Metallurgical Processing, TMS (Thermals, Metals and materials society) (2013)

3. Salimijazi, H., Hosseini, M., Mostaghimi, J., Pershin, L., Coyle, T.W., Smadi, H., Shafyei, A.: Plasma sprayed coating using mullite and mixed alumina/silica powder. J. Therm. Spray Technol. 21, 825-830 (2012)

4. Fauchais, P., Vardelle, M., Vardelle, A.: Reliability of plasmasprayed coatings: monitoring the plasma spray process and improving the quality of coatings. J. Phys. D Appl. Phys. 46, 224016 (2013)

5. Mahamad Sahab, A.R., Hayati Saad, N., Kasolang, S., Saedon, J.: Impact of plasma spray variables parameters on mechanical and wear behavior of plasma sprayed $\mathrm{Al}_{2} \mathrm{O}_{3} 3 \%$ wt $\mathrm{TiO}_{2}$ coating in abrasion and erosion application. Proc. Eng. 41, 1689-1695 (2012)

6. Xing, Y., Li, X., Zhang, Y., Jiang, C., Zhang, W.: Effect of plasma spray parameters on the splashing of plasma sprayed cost iron particles. J. Wuhan Univ. Technol. Mater. Sci. Ed. 31, 399-403 (2016)

7. Pan, W.X., Meng, X., Chen, X., Wu, C.K.: Experimental study on the thermal argon plasma generation and jet length change characteristics at atmospheric pressure. Plasma Chem. Plasma Process. 26, 335-345 (2006)
8. Vijay, M., Selvarajan, V., Yugeswaran, S., Ananthapadmanabhan, P.V., Sreekumar, K.P.: Effect of spraying parameters on deposition efficiency and wear behavior of plasma sprayed alumina-titania composite coatings. Plasma Sci. Technol. 11(6), 666 (2009)

9. Wang, L., Fang, J.C., Zhao, Z.Y.: Application of backward propagation network for forecasting hardness and porosity of coatings by plasma spraying. Surf. Coat. Technol. 201, 5085-5089 (2007)

10. Zhang, X.C., Xu, B.S., Wu, Y.X., Xuan, F.Z., Tu, S.T.: Porosity, mechanical properties, residual stresses of supersonic plasma sprayed Ni-based alloy coatings prepared at different powder feed rates. Appl. Surf. Sci. 254, 3879-3889 (2008)

11. Vautherin, B., Planche, M.-P., Bolot, R., Quet, A., Biachi, L., Montavon, G.: Vapors and droplets mixture deposition of metallic coatings by very low pressure plasma spraying. J. Thermal Spray Technol. 23, 596-608 (2014)

12. Venkataraman, R., Dasa, G., Singh, S.R., Pathak, L.C., Ghosha, R.N., Venkataraman, B., Krishnamurthy, R.: Study on influence of porosity, pore size, spatial and topological distribution of pores on micro-hardness of as plasma sprayed ceramic coating. Mater. Sci. Eng. 445, 269-274 (2007)

13. Hou, G., Zhao, Y., Zhou, H., Chen, J.: Effect of critical plasma spray parameter on microstructure and wear behavior of mullite coatings. Tribol. Int. 94, 138-145 (2016)

14. Fleury, E., Lee, S.M., Kim, W.T., Kim, D.H.: Effect of air plasma spraying parameters on $\mathrm{Al}-\mathrm{Cu}-\mathrm{Fe}$ quasicristalline coating layer. J. Non-Cryst. Solids 278, 194-204 (2000)

15. Vautherin, B., Planche, M.P., Montavon, G., Lapostolle, F., Quet, A., Biachi, L.: Study of metallic powder behavior in very low pressure plasma spraying (VLPPS)—Application to manufacturing of titanium-aluminum coatings. Surf Coat Technol 275, 341-348 (2015)

16. Han, M.S., Woo, Y.B., Ko, S.C., Jeong, Y.J., Jang, S.K., Kim, S.J.: Effects of thickness of Al thermal spray coating for STS 304. Trans. Nonferrous Met. Soc. Chin. 19, 925-929 (2009)

17. Abedi Esfahani, E., Salimijazi, H., Golozar, Mohamad A., Mostaghimi, J., Pershin, L.: Study of corrosion behaviour of arc sprayed aluminum coating on mild steel. J. Therm. Spray Technol. 21, 1195-1202 (2012)

18. Rahbek, O., Kold, S., Bendix, K., Overgaard, S., Soballe, K.: Superior sealing of hydroxyapatite in porous-coated implants. Acta Orthop. 76, 375-385 (2005)

19. Kumar, S., Selvarajan, V., Padmanabhan, P.V.A., Sreekumar, K.P.: Characterization and comparison between APS coatings prepared from ball milled and plasma processed nickel-aluminum powder. Mater. Sci. Surf. Eng. A 488, 287-294 (2008) 